\title{
Impact of the Lockdown Due to COVID-19 Pandemic on the Spectrum and Outcome of Trauma in India
}

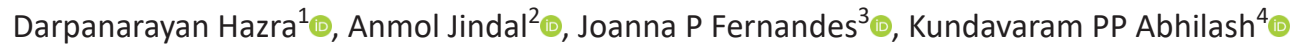

\begin{abstract}
Background: As a pre-emptive measure against the rampaging severe acute respiratory syndrome coronavirus 2 (SARS CoV-2), the Government of India ordered an unprecedented but imperative step of a nationwide lockdown on 22nd March, 2020. The entire month of April 2020 remained in a complete national lockdown.

Methodology: We conducted this retrospective study to compare the spectrum and outcome of trauma victims who presented to our emergency department (ED) from April 2020 (lockdown period) to a similar season matched control arm of April 2018 (non-lockdown period).

Results: Our study groups included 403 trauma victims (trauma prevalence: 9.7\%) from April 2020 as compared to 667 trauma victims (trauma prevalence: 10.8\%) from April 2018 with an absolute decrease of $-39.6 \%$ during the lockdown month. The intense lockdown resulted in an absolute decrease in the number of road traffic accidents (RTA) $(-75.1 \%)$, sports-related injuries $(-81.8 \%)$, bull gore injuries $(-64.3 \%)$, workplacerelated injuries $(-50.0 \%)$, and fall from height $(-3.5 \%)$. However, an absolute increase in the number of falls on level ground (FLG) (+95.7\%), domestic trauma $(+91.4 \%)$, and burn $(+37.5 \%)$ patients were noted during the lockdown period. The proportion of trauma victims under the influence of alcohol, as determined by a positive blood alcohol content, was significantly lower in the lockdown period (adjusted OR: 0.34 ( $95 \%$ Cl: 0.17-0.67); $p$-value: 0.002 ) as were RTAs (adjusted OR: 0.44 (95\% Cl: 0.31-0.62); $p$-value: <0.001), FLG (adjusted OR: 1.87 (95\% Cl: 1.14-3.06); p-value: 0.0 ), and head injuries (adjusted OR: 0.21 (95\% Cl: 0.13-0.3); $p$-value: <0.001).

Conclusion: During the stringent lockdown period of April 2020, there was a significant absolute decrease in the number of trauma victims, especially RTAs. The intense lockdown resulted in a significant decrease in the proportion of trauma victims under the influence of alcohol, head injuries, fractures, and dislocations.
\end{abstract}

Keywords: COVID-19, Emergency department, Lockdown, Pandemic, Road traffic accidents, Trauma.

Indian Journal of Critical Care Medicine (2021): 10.5005/jp-journals-10071-23758

\section{INTRODUCTION}

As the COVID-19 pandemic brought the world to a grinding halt in the first half of 2020, leaders and medical experts grappled with this mammoth challenge of controlling the spread of the contagion. As a pre-emptive measure against this invisible adversary, on 24th March, 2020, the Government of India ordered an unprecedented nationwide lockdown for 21 days and subsequently extended till May 2020 to minimize the movement of the 1.3 billion population of India. ${ }^{1-3}$ This absolutely indispensable and globally appreciated rigorous lockdown froze the World's largest democracy in its tracks. There was a complete embargo on almost all types of public and private transport, while all educational and training centers, factories, industries, and offices were forced to stay shut. All non-essential stores and notably liquor shops were prohibited to operate during this period of crisis. ${ }^{4-6}$ In the past few decades, accelerated motorization and urbanization had led to an alarming increase in the rate of accidental injuries, making trauma one of the leading causes of mortality in India. Although India has only $1 \%$ of the motor vehicles of the world, we bear the burden of $6 \%$ of the total global vehicular accidents.,

However, due to the lockdown, a billion people were forced to stay behind closed doors and the usually bustling streets and national highways, including the golden quadrilateral and the massive expressways across the country, bore an unfamiliar deserted look. More than 100 million Indians, mainly daily wage workers like hawkers, roadside vendors, construction workers, and those who eke out a living by physical labor were forced out of their jobs. This
${ }^{1-4}$ Department of Emergency Medicine, Christian Medical College and Hospital, Vellore, Tamil Nadu, India

Corresponding Author: Kundavaram PP Abhilash, Department of Emergency Medicine, Christian Medical College and Hospital, Vellore, Tamil Nadu, India, Phone: +91 9994924743, e-mail: kppabhilash@ gmail.com

How to cite this article: Hazra D, Jindal A, Fernandes JP, Abhilash KPP. Impact of the Lockdown Due to COVID-19 Pandemic on the Spectrum and Outcome of Trauma in India. Indian J Crit Care Med 2021;25(3): 273-278.

Source of support: Nil

Conflict of interest: None

"lockdown generation" was forced to live within the confines of their homes with minimal friction, which is a pre-requisite for trauma. In this milieu, we expected the prevalence of trauma to decrease and the spectrum to have shown a significant change. But what was the exact impact of the lockdown on the gamut and outcome of trauma presenting to the emergency departments (ED) compared to a period of tranquility in our country? This was the intriguing question we sought to answer through this study.

\section{Methodology}

Study Design

This was a retrospective cross-sectional study.

() Jaypee Brothers Medical Publishers. 2021 Open Access This article is distributed under the terms of the Creative Commons Attribution 4.0 International License (https://creativecommons.org/licenses/by-nc/4.0/), which permits unrestricted use, distribution, and non-commercial reproduction in any medium, provided you give appropriate credit to the original author(s) and the source, provide a link to the Creative Commons license, and indicate if changes were made. The Creative Commons Public Domain Dedication waiver (http://creativecommons.org/publicdomain/zero/1.0/) applies to the data made available in this article, unless otherwise stated. 


\section{Study Setting}

The study was conducted in the ED of a large tertiary care hospital in South India. Our ED is a 49-bed department and usually tends to about 75,000 patients per year including trauma and non-trauma patients.

\section{Participants}

All trauma patients who presented with trauma during the lockdown month of April 2020 and a comparative period of April 2018 were screened.

\section{Inclusion Criteria}

We included patients who presented to our ED with a history of road traffic accidents (RTA), fall from height or fall on level ground, domestic accidental injuries, injuries, sports-related injuries, assault injures, or injuries caused by animals.

\section{Exclusion Criteria}

Patients who were brought dead to the ED following trauma and charts with missing data were excluded.

\section{Variables}

We collected data on trauma patients from our hospital's electronic database. The following data were collected on a standard data abstraction sheet: baseline characteristics, mode of injury, type of RTA, blood alcohol content (BAC), triage priority level, injury severity score (ISS), ED management, and hospital outcome. Triaging of trauma victims was done by standard Canadian triage system and is summarized as follows:

- Triage priority I: Patients with compromised airway, breathing or circulatory status, and severe head injury with Glasgow coma scale $($ GCS $) \leq 8$.

- Triage priority Il: Patient with a patent airway, and no breathing or circulatory compromise. These included patients with long bone injuries, stable abdomino-thoracic injuries, and mild to moderate head injury.

- Triage priority 3: Patients with minor trauma without any hemodynamic instability.

\section{Outcome Variable}

The outcome measures were the severity of trauma and mortality rate comparing April 2020 and April 2018. The ISS is an anatomical scoring system of the severity of trauma and is calculated by the sum of the squares of the highest abbreviated injury scale (AIS) severity score in each of the three most severely injured body regions. $^{9}$

\section{Laboratory Tests}

After performing the primary and secondary survey, the ED registrar or physicians sent relevant blood investigations and radiological imaging.

\section{Bias}

This was a retrospective study; therefore, we could not control exposure or outcome assessment, and instead relied on others for accurate record keeping.

\section{Study Size}

We aimed to study the prevalence of trauma patients during the lockdown period compared to the same month in 2018, hence all patients presenting to the ED with trauma during the two study periods of April 2018 and April 2020 were included.

\section{Statistical Analysis}

We analyzed the data by using a statistical package for social sciences for Windows (SPSS Inc. released 2007, version 23.0. Armonk, NY, USA). Continuous variables were expressed as mean with standard deviation and nominal variables as numbers and percentages. Dichotomous variables were compared by using the chi-square test. The factors associated with the profile of trauma patients during these two study periods were determined by bivariate followed by multivariate logistic regression analysis and their $95 \%$ confidence intervals $(\mathrm{Cl})$ calculated. A two-sided $p$-value of less than 0.05 was considered statistically significant.

\section{Ethical Considerations}

Approval by the Institutional Review Board and Ethics Committee (IRB Min. No. 12855 dated 13.05.2020) were obtained before the commencement of this study. Unique identifiers and passwordprotected data entry software were used by the primary investigators to maintain patient confidentiality.

\section{Results}

Our study groups included 403 trauma victims (trauma prevalence: 9.7\%) during April 2020 and 667 trauma victims (trauma prevalence: 10.8\%) during April 2018 with an absolute decrease of $-39.6 \%$ during the lockdown period (Fig. 1).

\section{Baseline Characteristics}

The mean age in both the periods was similar; 33.94 (SD: 21.48) years in April 2020 vs 35.83 (SD: 18.8) years in April 2018. There was a male preponderance of $68.7 \%$ in 2020 and $75 \%$ in 2018 . The proportion of the middle age group and geriatric trauma remained

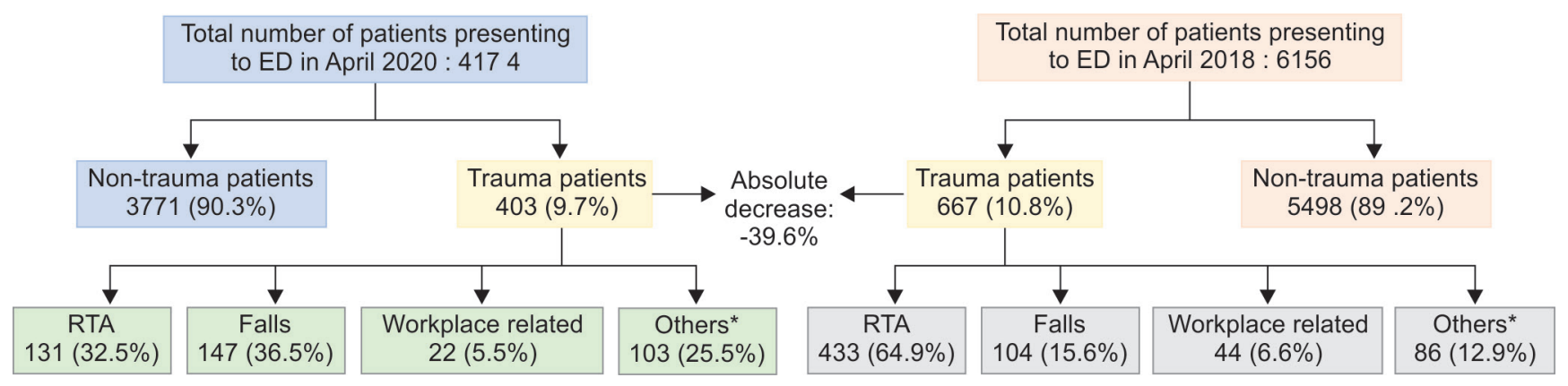

Fig. 1: STROBE diagram 
Impact of COVID-19 Lockdown on Trauma

Table 1: Baseline patient's characteristics of trauma patients with an absolute difference between the two periods

\begin{tabular}{|c|c|c|c|c|}
\hline Characteristics & $\begin{array}{l}\text { April } 2020 \\
\text { Frequency (\%) }\end{array}$ & $\begin{array}{l}\text { April } 2018 \\
\text { Frequency (\%) }\end{array}$ & Absolute difference $(n)^{*}$ & Absolute difference $(\%)^{\#}$ \\
\hline Total number of patients & 403 & 667 & -264 & -39.58 \\
\hline Mean age in years (SD) & $33.94(21.48)$ & $35.83(18.8)$ & $\begin{array}{l}-1.89(-4.34 \text { to } 0.57) \\
p \text {-value }=0.13\end{array}$ & \\
\hline \multicolumn{5}{|l|}{ Time of arrival } \\
\hline $8 \mathrm{am}-5 \mathrm{pm}$ & $210(52.1)$ & $280(42.0)$ & -70 & -25.00 \\
\hline $5 \mathrm{pm}-12 \mathrm{am}$ & $146(36.2)$ & $284(42.6)$ & -138 & -48.59 \\
\hline $12 \mathrm{am}-8 \mathrm{am}$ & $47(11.7)$ & $103(15.4)$ & -56 & -54.37 \\
\hline Males & $277(68.7)$ & $500(75.0)$ & -223 & -44.60 \\
\hline Females & $126(31.3)$ & $167(25.0)$ & -41 & -24.55 \\
\hline \multicolumn{5}{|l|}{ Age category } \\
\hline Pediatric and adolescent trauma ( $<18$ years) & $105(26.1)$ & $100(15)$ & 5 & 5.00 \\
\hline Adult trauma ( $18-59$ years) & $246(61.0)$ & $478(71.7)$ & -232 & -48.54 \\
\hline Geriatric trauma ( $\geq 60$ years) & $52(12.9)$ & $89(13.3)$ & -37 & -41.57 \\
\hline \multicolumn{5}{|l|}{ Triage priority levels } \\
\hline Priority 1 & $30(14.9)$ & $100(15)$ & -70 & -70.00 \\
\hline Priority 2 & $116(57.4)$ & $366(54.9)$ & -250 & -68.31 \\
\hline Priority 3 & $56(27.7)$ & $199(29.8)$ & -143 & -71.86 \\
\hline$I S S \geq 14$ & $30(7.4)$ & $28(4.2)$ & 2 & 7.14 \\
\hline BAC detected & $19(4.7)$ & $112(16.8)$ & -93 & -83.03 \\
\hline
\end{tabular}

*Absolute difference = number in the year 2018 - number in the year 2020; ${ }^{*} \%$ = absolute difference/number in 2018; BAC, blood alcohol levels; ISS, injury severity score

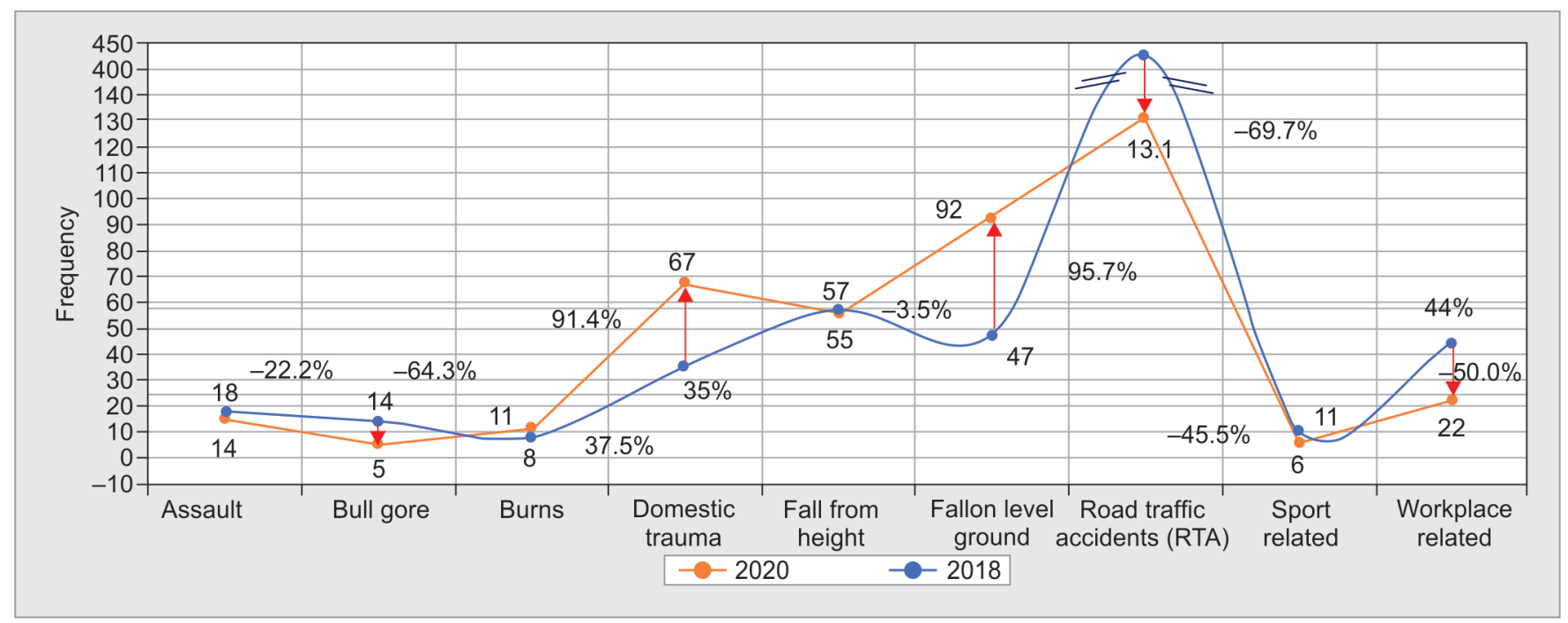

Fig. 2: Modes of trauma comparing April 2020 and April 2018 with an absolute difference in each year

the same in both periods but with a significant absolute decrease of $-232(-48.54 \%)$ and $-37(-41.57 \%)$, respectively. The proportion of patients with the triage priority levels in the two periods were similar (Table 1). The proportion of patients under the influence of alcohol as determined by a positive BAC was significantly lower in the lockdown month of April 2020 (4.7\%) compared to April 2018 $(16.8 \%)$ with an absolute difference of -93 .

\section{Mode and Severity of Trauma}

During the lockdown period, the absolute number of RTAs decreased by $75.1 \%$ (131 in April 2020 vs 433 in April 2018). The intense lockdown in April 2020 also resulted in an absolute decrease in the number of sports-related injuries $(-81.8 \%)$, bull gore injuries $(-64.3 \%)$, workplace-related injuries $(-54.5 \%)$, assault $(-44.4 \%)$, and fall from height $(-54.4 \%)$. However, an absolute increase in fall on level ground (95.7\%), domestic trauma (91.4\%), and burnrelated injuries (37.5\%) were noted during the lockdown period (Fig. 2). Among the RTA, there was a significant absolute decrease in the number of auto $(-100 \%)$, bus or lorry $(-90 \%)$, four-wheeler $(-86.7 \%)$, pedestrian-related injuries $(-85.0 \%)$, and two-wheeler accidents (-64.6\%) (Fig. 3). Surprisingly, the proportion of patients with severe trauma as defined by ISS > 14 was significantly higher 


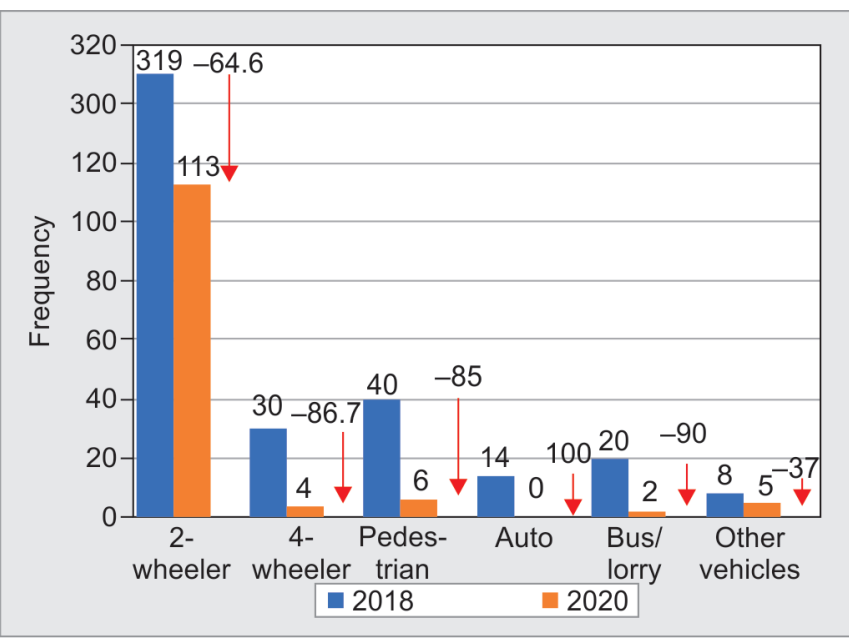

Fig. 3: Types of road traffic accidents comparing April 2020 and April 2018 with an absolute difference in each year
Table 3: Emergency department and hospital outcome related to trauma in 2020 vs 2018

\begin{tabular}{|c|c|c|c|c|}
\hline ED outcome & $\begin{array}{l}\text { Frequency } \\
\text { (\%) } \\
\text { April } 2020 \\
n=403\end{array}$ & $\begin{array}{l}\text { Frequency } \\
\text { (\%) } \\
\text { April } 2018 \\
n=667\end{array}$ & $\begin{array}{l}\text { Absolute } \\
\text { difference } \\
\text { (N) }\end{array}$ & $\begin{array}{l}\text { Absolute } \\
\text { difference } \\
(\%)\end{array}$ \\
\hline Admission & $92(22.8)$ & $170(25.5)$ & -78 & $-45.88 \%$ \\
\hline Discharged stable & $293(72.8)$ & $468(70.2)$ & -175 & $-37.39 \%$ \\
\hline Death & 0 & $2(0.3)$ & -2 & $-100.00 \%$ \\
\hline $\begin{array}{l}\text { Left against medical } \\
\text { advice }\end{array}$ & $12(3)$ & $17(2.5)$ & -5 & $-29.41 \%$ \\
\hline $\begin{array}{l}\text { Left against medical } \\
\text { advice due to poor } \\
\text { prognosis }\end{array}$ & $6(1.4)$ & $10(1.5)$ & -4 & $-40.00 \%$ \\
\hline Hospital outcome & $n=92$ & $n=170$ & & \\
\hline Discharged stable & $90(97.8)$ & $167(98.2)$ & -77 & $-46.11 \%$ \\
\hline Death & $1(1.1)$ & $3(1.8)$ & -2 & $-66.67 \%$ \\
\hline $\begin{array}{l}\text { Left against medical } \\
\text { advice }\end{array}$ & $1(1.1)$ & 0 & 1 & NA \\
\hline
\end{tabular}

Table 2: Bivariate and multivariate logistic regression analysis for factors related to trauma in 2020 vs 2018

\begin{tabular}{|c|c|c|c|c|c|c|}
\hline Variables & $\begin{array}{l}\text { April } 2020 \\
\text { Frequency } \\
n=402 \text { (\%) }\end{array}$ & $\begin{array}{l}\text { April } 2018 \\
\text { Frequency } \\
n=667(\%)\end{array}$ & $p$-value & Unadjusted odds ratio & p-value & Adjusted odds ratic \\
\hline Males & $277(68.7)$ & $500(75)$ & 0.027 & $0.73(0.56-0.97)$ & 0.83 & $1.04(0.74-1.45)$ \\
\hline Pediatric ( $<18 \mathrm{yrs}$ ) and geriatric ( $\geq 60 \mathrm{yrs}$ ) trauma & $157(39.0)$ & $189(28.3)$ & $<0.001$ & $1.61(1.24-2.10)$ & 0.10 & $1.32(0.95-1.82)$ \\
\hline Religion-Hindus & $349(86.6)$ & $614(92.1)$ & 0.004 & $0.56(0.37-0.83)$ & 0.37 & $0.81(0.51-1.29)$ \\
\hline RTA vs others & $131(32.5)$ & $433(64.9)$ & $<0.001$ & $0.26(0.20-0.34)$ & $<0.001$ & $0.44(0.31-0.62)$ \\
\hline Assault & $14(3.5)$ & $18(2.7)$ & 0.47 & $1.30(0.64-2.64)$ & & \\
\hline Fall from height & $55(13.6)$ & $57(8.5)$ & 0.008 & $1.70(1.14-2.51)$ & 0.42 & $1.23(0.74-2.05)$ \\
\hline Fall on ground level & $92(22.8)$ & $47(7.0)$ & $<0.001$ & $3.90(2.68-5.69)$ & 0.013 & $1.87(1.14-3.06)$ \\
\hline $\mathrm{H} / \mathrm{O}$ alcohol consumption & $8(2)$ & $46(6.9)$ & $<0.001$ & $0.27(0.13-0.59)$ & 0.90 & $0.93(0.34-2.61)$ \\
\hline BAC detected & $19(4.7)$ & $112(16.8)$ & $<0.001$ & $0.25(0.15-0.41)$ & 0.002 & $0.34(0.17-0.67)$ \\
\hline Pulse $>100 \mathrm{~b} / \mathrm{min}$ & 79 (19.6) & $211(31.6)$ & $<0.001$ & $0.53(0.39-0.71)$ & 0.001 & $0.55(0.39-0.78)$ \\
\hline $\mathrm{SBP}<90 \mathrm{~mm} \mathrm{Hg}$ & $6(1.5)$ & $17(2.5)$ & 0.25 & $0.58(0.23-1.48)$ & & \\
\hline $\mathrm{SpO}_{2}<94 \%$ & $6(1.5)$ & $43(6.4)$ & $<0.001$ & $0.22(0.09-0.52)$ & 0.004 & $0.21(0.07-0.61)$ \\
\hline GCS & $10(2.5)$ & $40(6)$ & 0.008 & $0.40(0.20-0.81)$ & 0.96 & $0.98(0.35-2.70)$ \\
\hline Head injury & $44(10.9)$ & $180(27.0)$ & 0.001 & $0.33(0.23-0.47)$ & $<0.001$ & $0.21(0.13-0.33)$ \\
\hline Fractures or dislocation & $171(44.1)$ & $437(65.6)$ & $<0.001$ & $0.39(0.30-0.50)$ & $<0.001$ & $0.20(0.15-0.28)$ \\
\hline ISS & $30(7.4)$ & $28(4.2)$ & 0.02 & $1.84(1.08-3.12)$ & $<0.001$ & $10.17(4.83-21.42)$ \\
\hline Discharge from ED & $293(72.7)$ & $468(70.2)$ & 0.37 & $1.13(0.86-1.49)$ & & \\
\hline
\end{tabular}

BAC, blood alcohol levels; ED, emergency department, GCS, Glasgow coma scale; ISS, injury severity score; RTA, road traffic accidents; SBP, systolic blood pressure

during the lockdown month of April 2020 (7.4\%) compared to April 2018 (4.2\%) (Table 1).

\section{Factors Related to Trauma in 2020 and 2018}

We performed bivariate and multivariate logistic regression analysis to determine the factors related to trauma during the lockdown month of April 2020 (Table 2). The following factors showed an independent and statistically significant decrease in proportion during the lockdown period of April 2020: positive BAC (adjusted OR: 0.34 (95\% Cl: 0.17-0.67); $p$-value: 0.002), fall on level grounds (adjusted OR: 1.87 (95\% Cl: 0.14-3.06); $p$-value: 0.013$)$, head injuries (adjusted OR: 0.21 (95\% Cl: 0.13-0.33); $p$-value: $<0.001$ ), and fractures or dislocations (adjusted
OR: 0.20 (95\% Cl: 0.15-0.28); $p$-value: <0.001). However, during the lockdown period, the adjusted odds ratio of presenting with severe trauma (ISS $\geq 14$ ) was 10.17 (95\% Cl: 4.83-21.42; $p$-value: <0.001).

\section{Hospital Outcome}

After initial resuscitation and stabilization, the trauma patients were referred to the appropriate surgical departments for further management if needed. During the lockdown month of April 2020, there was a $-45.88 \%$ (78) absolute decrease in in-patient admissions. The in-hospital mortality rate of trauma victims decreased to $0.24 \%$ (1/403) during April 2020 from 0.74\% (5/667) during April 2018 (Table 3). 


\section{Discussion}

As anticipated, our study showed a clear decline in the prevalence of trauma during the lockdown period. RTAs account for the highest proportion of trauma incidents in India. ${ }^{10,11}$ Our study showed an absolute decrease of cases by $75.1 \%$ during the lockdown period. The stern lockdown created a "curfew" across the country and the restrictions on time for travel to stock up only essential commodities resulted in reduced traffic that directly led to reduced incidence of RTA. Amidst the doom and gloom of the lockdown, the decrease in trauma victims in our state was a great relief, especially in the context of Tamil Nadu having one of the highest numbers of road collisions in the country.

We found a slight increase in the proportion of the pediatric population between the two periods, $26.1 \%$ in 2020 compared to $15 \%$ in 2018 , although the proportion was not statistically significant. It could be surmised that as schools were closed, children had more time for other activities, making them more prone to injuries secondary to indoor and outdoor games. ${ }^{12}$ The increase in proportions of trauma incidents during the morning hours could be explained by a strict night curfew (7 PM-7 AM) enforced during April 2020 that compelled the public to stay indoors. ${ }^{1}$ Workplace-related injuries also declined owing to a complete shutdown of micro, small, and medium enterprises and other jobs, such as mining, carpentry, and agricultural fieldwork. ${ }^{13-15}$ The number of assault-related injuries, although lower than in past years, was still much higher than expected despite police surveillance. ${ }^{16,17}$ This is a potential indicator of the huge psychological and economic impact of lockdown on the general population and should be further surveyed in detail. The pan-global lockdown has aptly been described as "the world's largest psychological experiment" ${ }^{18-20}$ A review of multiple studies done on the effect of quarantine published by The Lancet shows that quarantine in the past has been associated with increased fear and anger among other emotions that may have perpetrated assaults. ${ }^{18}$

A previous systemic review estimated that BAC more than $30 \mathrm{mg} / \mathrm{dL}$ is responsible for $2-3 \%$ of trauma cases and $6-48 \%$ of deaths with RTAs. ${ }^{21,22}$ During the lockdown period, there was a restriction placed over the sale of alcohol. Hence, the number of cases with positive BAC significantly decreased. Although the legal limit for BAC in India is $30 \mathrm{mg} / \mathrm{dL}$, considering the delay from the time of the incident to the time of arrival to our center, we assumed victims to be under the influence of alcohol by positive BAC value. ${ }^{22}$ We can hereby speculate that the conscientious sale of alcohol will help in a reduction in the incidence of trauma. Though there was a decline in the number of trauma victims, ironically the threat of severe trauma as determined by ISS $\geq 14$ was 10.17 times more as compared to April 2018. Yet the plausibility of sustaining a head injury and fractures or dislocation was lower as seen in other studies as well. ${ }^{23,24}$ This can be attributed to the fact that many victims with minor injuries did not seek medical attention due to the lockdown, and thereby highlighting the unfortunate consequence of lockdown.

To sum up, though the nationwide lockdown in early 2020 has varyingly been described as indispensable, stern, stringent, and even draconian, our study shows an undeniable silver lining in the decreased incidence of trauma, especially RTAs and in the decrease in the consumption of alcohol.

\section{Strengths of OUr Study}

This is one of the first studies from India that showed the precise impact of the total lockdown imposed during the early stage of the COVID pandemic on the spectrum and outcome of trauma. Our study also objectively showed the beneficial result of the associated prohibition of liquor shops during the lockdown period on trauma.

\section{Limitations}

This is data from a single large tertiary care center that may have resulted in patient selection and an inherent referral pattern bias. Missing patient records and incomplete data were other limitations of our retrospective study.

\section{Conclusion}

During the lockdown period of April 2020, there was a significant decrease in the prevalence of trauma, especially RTAs. There was a significant decrease in the proportion of trauma patients under the influence of alcohol and also the proportion of head injuries, fractures, and dislocations. However, there were higher odds of presenting with severe trauma, despite the intense lockdown enforced.

\section{Research Quality and Ethics Statement}

All authors of this manuscript declare that this scientific study complies with standard reporting guidelines set forth by the EQUATOR Network. The authors ratify that this study required Institutional Review Board/Ethics Committee review, and hence prior approval was obtained, IRB Min. No. 12855 dated 13.05.2020). We also declare that we did not plagiarize the contents of this manuscript and have performed a Plagiarism Check.

\section{ORCID}

Darpanarayan Hazra (1) https://orcid.org/0000-0002-5941-0587

Anmol Jindal @ https://orcid.org/0000-0001-6373-0316

Joanna P Fernandes (1) https://orcid.org/0000-0001-8246-9037

Kundavaram PP Abhilash 간 https://orcid.org/0000-0002-2382-4411

\section{References}

1. PM Narendra Modi announces a national lockdown for 21 days starting midnight of 24-25 March-Firstpost [Internet]. [cited 2020 May 27]. Available from: https://www.firstpost.com/health/ pm-narendra-modi-announces-a-national-lockdown-for-21-daysstarting-midnight-of-24-25-march-8185961.html.

2. From midnight, entire country shall go under complete lockdown: PM Modi [Internet]. www.narendramodi.in. [cited 2020 May 27]. Available from: https://www.narendramodi.in/text-of-primeminister-narendra-modi-s-address-to-the-nation-on-vital-aspectsrelating-to-the-menace-of-covid-19-548941.

3. Hebbar N. Coronavirus | PM's address to the nation updates: lockdown extended to the entire country for next 21 days, says Modi. The Hindu [Internet]. 2020 Mar 24 [cited 2020 May 27]. Available from: https://www.thehindu.com/news/national/prime-ministernarendra-modi-live-updates-march-24-2020/article31153585.ece.

4. Sreekumar G, Lohanathan A, Hazra D. COVID-19-a replay of the 1918 pandemic? Curr Med Issues 2020;18(2):83-86. DOI: 10.4103/cmi. cmi_36_20.

5. India's 1.3bn population told to stay at home. BBC News [Internet]. 2020 Mar 25 [cited 2020 May 27]. Available from: https://www.bbc. com/news/world-asia-india-52024239.

6. Jeffery A, Miller H. Coronavirus puts over 1 billion people in India on 21-day lockdown to combat spread [Internet]. CNBC 2020 [cited 2020 May 27]. Available from: https://www.cnbc.com/2020/03/26/ coronavirus-puts-over-1-billion-people-in-india-on-21-daylockdown-to-combat-spread.html.

7. Mohan D. Road safety in less-motorized environments: future concerns. Int J Epidemiol 2002;31(3):527-532. DOI: 10.1093/ije/31.3.527. 
8. Abhilash KPP, Chakraborthy N, Pandian GR, Dhanawade VS, Bhanu TK, Priya K. Profile of trauma patients in the emergency department of a tertiary care hospital in South India. J Family Med Prim Care 2016;5(3):558-563. DOI: 10.4103/2249-4863.197279.

9. Baker SP, O'Neill B, Haddon W, Long WB. The injury severity score: a method for describing patients with multiple injuries and evaluating emergency care. J Trauma 1974;14(3):187-196.

10. Dkhar I, Hazra D, Madhiyazhagan M, Joseph J, Abhilash KP. A retrospective study on the profile of long bone injuries in trauma patients presenting to emergency department. Curr Med Issues 2019;17(3):60-65. DOI: 10.4103/cmi.cmi_35_19.

11. Christey G, Amey J, Campbell A, Smith A. Variation in volumes and characteristics of trauma patients admitted to a level one trauma centre during national level 4 lockdown for COVID-19 in New Zealand. N Z Med J 2020;133(1513):81-88.

12. Kids locked at home all day are a recipe for accidental injuries and visits to the ER | Sadiqa AI Kendi | Opinion | The Guardian [Internet]. [cited 2020 May 31]. Available from: https://www.theguardian. com/commentisfree/2020/apr/24/children-accidental-injuriescoronavirus-lockdown

13. COVID-19: lockdown-hit MSMEs in Andhra Pradesh stare at bleak future-The New Indian Express [Internet]. [cited 2020 May 31]. Available from: https://www.newindianexpress.com/states/andhrapradesh/2020/apr/09/covid-19-lockdown-hit-msmes-in-andhrapradesh-stare-at-bleak-future-2127798.html.

14. MHA guidelines on lockdown: complete text of guidelines for lockdown 2.0 | India News-Times of India [Internet]. [cited 2020 May 31]. Available from: https://timesofindia.indiatimes.com/india/ govt-fresh-guidelines-for-lockdown-2-0-whats-shut-whats-openfrom-april-20/articleshow/75152832.cms.

15. Coronavirus lockdown: unable to harvest, farmer burns sugarcane crop worth ₹ 2 lakh-The Hindu [Internet]. [cited 2020 May 31]. Available from: https://www.thehindu.com/news/national/ karnataka/coronavirus-lockdown-unable-to-harvest-farmer-burnssugarcane-crop-worth-2-lakh/article31493576.ece.

16. Domestic violence during Covid-19 lockdown emerges as serious concern—IndiaNews_Hindustan Times [Internet]. [cited 2020 May31].
Available from: https://www.hindustantimes.com/india-news/ domestic-violence-during-covid-19-lockdown-emerges-as-seriousconcern/story-mMRq3NnnFvOehgLOOPpe8J.html.

17. Across Tamil Nadu, caste violence has increased during the lockdown, say activists [Internet]. The Wire. [cited 2020 May 31]. Available from: https://thewire.in/caste/tamil-nadu-caste-atrocities-lockdown.

18. Brooks SK, Webster RK, Smith LE, Woodland L, Wessely S, Greenberg $\mathrm{N}$, et al. The psychological impact of quarantine and how to reduce it: rapid review of the evidence. Lancet 2020;395(10227):912-920. DOI: 10.1016/S0140-6736(20)30460-8.

19. Mitigating psychological effects of lockdowns [Internet]. National Association of School Psychologists (NASP). [cited 2020 May 31]. Available from: https://www.nasponline.org/ resources-and-publications/resources-and-podcasts/schoolclimate-safety-and-crisis/systems-level-prevention/mitigatingpsychological-effects-of-lockdowns.

20. Lockdown is the world's biggest psychological experiment-and we will pay the price [Internet]. World Economic Forum. [cited 2020 May 31]. Available from: https://www.weforum.org/agenda/2020/04/ this-is-the-psychological-side-of-the-covid-19-pandemic-that-wereignoring/.

21. Das A, Gjerde H, Gopalan SS, Normann PT. Alcohol, drugs, and road traffic crashes in India: a systematic review. Traffic Inj Prev 2012;13(6):544-553. DOI: 10.1080/15389588.2012.663518.

22. Prabhakar Abhilash KP, Lath D, Kowshik J, Jose A, Chandy GM. Blood alcohol levels in road traffic accidents: Factors associated and the relationship between history of alcohol consumption and blood alcohol level detection. Int J Crit IIIn Inj Sci 2019;9(3):132-137. DOI: 10.4103/IJCIIS.IJCIIS_45_19.

23. Khak M, Shakiba S, Rabie H, Naseramini R, Nabian MH. Descriptive epidemiology of traumatic injuries during the first lockdown period of COVID-19 crisis in Iran: a multicenter study. Asian J Sports Med. 2020;11(2):e103842. DOI: 10.5812/asjsm.103842.

24. Hampton M, Clark M, Baxter I, Stevens R, Flatt E, Murray J, et al. The effects of a UK lockdown on orthopaedic trauma admissions and surgical cases. Bone Jt Open 2020;1(5):137-143. DOI: 10.1302/26331462.15.BJO2020-0028.R1. 